Working Paper

REFORMING STANDARD-SETTING

Giandomenico Majone

September 1982

WP-82-90

International Institute for Applied Systems Analysis A-2361 Laxenburg, Austria 
NOT FOR QUOTATION

WITHOUT PERMISSION

OF THE AUTHOR

\section{REFORMING STANDARD-SETTING}

Giandomenico Majone

September 1982

WP $-82-90$

Working Papers are interim reports on work of the International Institute for Applied Systems Analysis and have received only limited review. Views or opinions expressed herein do not necessarily represent those of the Institute or of its National Member Organizations.

INTERNATIONAL INSTITUTE FOR APPLIED SYSTEMS ANALYSIS A-2361 Laxenburg, Austria 


\author{
REFORMING STANDARD-SETTING* \\ Giandomenico Majone \\ Zentrum fur interdisziplinare Forschung \\ University of Bielefeld, Federal Republic of Germany
}

1. Environmental, health, and safety standards are, and will long remain, basic instruments of regulatory policy. At the same time, the standard-setting process rests on precarious conceptual, scientific, and economic foundations. This contradiction poses delicate problems of administrative rationality and political legitimacy. For example, the demand for "conclusive" scientific evidence and thorough risk analyses before a standard is adopted, is more likely to delay public action than to improve the quality of decision-making, and to generate dissension rather than consensus.

What is needed is a fundamental restructuring of procedures, institutions, and regulatory philosophies along lines that explicitly recognize the uncertainty and complexity of regulatory decisions. Three directions of regulatory reform seem to be particularly important. First, statutory regulations should be replaced as much as possible by nonstatutory codes and standards. This implies, among other things, a novel style of consultative regulation and inspection with participative overtones.

Second, a distinction should be drawn between environmental and health goals, on the one hand, and currently feasible levels of protection, on the other. This distinction is consistent with the philosophy of West European and soviet regulators, and with the attitudes of many scientists in both East and West.

*Forthcoming in Journal of Policy Analysis and Management, December 1982 . 
Third, greater attention should be paid to the procedural aspects of standard-setting. Given the level of cognitive complexity facing regulators, the substantive rationality of regulatory decisions cannot be judged independently of their procedural rationality.

2. Concerning the first point -- the need for greater regulatory flexibility -- it is clear that environmental, health, and safety standards should be revised as scientific knowledge improves, empirical evidence accumulates, and socioeconomic conditions and public perceptions change. However, frequent revisions are unlikely (or very costly) when standards are embedded in legal codes. Also, the more uncertain the scientific basis of regulation and the greater the need for flexibility and adaptability, the more discretion should be left to the regulatory agency. But statutory regulation sets narrow limits to administrative discretion.

The experience of a number of European countries shows that an effective regulatory system can be operated without heavy reliance on legally enforceable standards. In the Federal Republic of Germany and in France, maximum acceptable concentrations (MACs) for toxic substances and other environmental limits are not embedded in legal codes but are used by the inspectors -- together with other information about the physical, chemical, and toxicological characteristics of different substances -- for giving preventive advice and monitoring working and environmental conditions. MAC values and standards are typically based on heal.th criteria only. Guidelines interpreting the standards in the light of technical and economic constraints are issued by separate governmental commissions, such as the Committee for Dangerous Materials in the Workplace set up by the German Federal Ministry of Labor and Social Affairs.

In the United Kingdom, too, occupational health standards hare no specific leral status, but are used by the Factory Inspectorate of the Department of Employment for control and surveillance of working conditions. A strong 
case for greater reliance on voluntary standards and codes is presented in the official report of the Parliamentary Committee appointed in May 1970 under the chairmanship of Lord Robens. Although the report deals with occupational health and safety, many of its arguments have more wideranging validity. The following recommendations of the Robens Committee are particularly relevant to the present discussion:

- Wherever practicable, regulations should be confined to statements of the broad objectives to be achieved.

- In future, no statutory regulations should be made before detailed consideration has been given to whether objectives might adequately be met by a non-statutory standard or code of practice.

- Greater emphasis should be placed on standard-setting by means of non-statutory codes and standards. As a general rule, statutory regulations should only be made when the non-statutory alternatives have been fully explored and found wanting.

- The whole regulatory system should be more flexible and more discriminating. Industry should be encouraged to deal with more of its own problems, thereby enabling official regulation to be more effectively concentrated on serious problems where strict official regulation is appropriate and necessary. ${ }^{1)}$

These recommendations express the belief that statutory regulations are largely ineffective, intrinsically rigid, and have a built-in tendency to become obsolete quite rapidly. On the other hand, "standards and codes developed within industry and by independent bodies are, over a large part of the field, more practical and therefore potentially more effective instruments of progress than statutory regulations."2) The Report concludes that what is needed is "less law" and more provision for voluntary self-regulation at the plant level. 
However, in order to provide credible sanctions when needed, inspectors should have the power, without reference to the courts, to issue formal Improvement Notices, i.e., orders to comply not only with any relevant statutory regulation, but also with any relevant voluntary code or standard that has been formally approved by the Authority for Safety and Health at Work. Voluntary codes and standards would also be admissible evidence in proceedings before tribunals. In cases where serious hazards or imminent dangers exist, the inspector could issue a Prohibition Notice ordering that, in the event of non-compliance within the stated time limit, the use of specified plant, machinery, processes or premises must be discontinued, or continued only under specific conditions.

But ensuring compliance with minimum legal requirements is not the main task of the inspectorate. Rather, inspectors should be concerned with the broad aspects of safety and health at the workplaces they visit, as much as with those narrow aspects which may have been the subject of detailed statutory regulations. "We believe," the Report states, "that, as a matter of explicit policy, the provision of skilled and impartial advice and assistance should be the leading edge of the unified inspectorate."3)

3. A second suggestion for regulatory reform involves drawing a distinction between long-run goals and currently feasible levels of protection. Here the approach of Soviet regulators is particularly instructive. Health standards, Soviet authorities maintain, should be based on health effects alone, without regard to the availability of adequate control technology, to economic feasibility, or even to the ability to adequately measure the concentrations in practice. A currently unattainable standard can still represent a guideline for enforcement and an incentive for future research in control technology. Conversely, since technically or economically attainable concentrations will coincide with harmless concentrations only by chance, standards based on 
considerations of economic or technical feasibility "can act only as an obstacle to the search for better techniques, ... they sanction what has already been achieved without stimulating new technical advances."4)

Since "scientifically based" standards cannot always be achieved, the Soviets also use secondary standards that may modify, for a limited period of time, the requirements set by the primary standards. During this time, the situation must be brought into conformity with the primary standards. It is claimed that if this approach is adopted, health standards will not be used to sanction existing technical and economic conditions, but will faithfully represent health policy goals.

It is not easy to determine the extent to which this regulatory philosophy is actually translated into practice; opinions among western experts differ. However, the criticism that standards used in the West tend to codify existing eccnomic and technical conditions, to the detriment of their normative character, has some validity. It is often said that one of the main goals of environmental and health standards is to channel growth away from hazardous indistries and materials toward safer forms of production and employment. But it is hard to see how a "feasible" standard (in the sense in which this term has been recently usea in the United states) can provide the necessary signals.

American regulators are constantly urged to treat economic and technical feasibility as important considerations in the derivation of standards. Responding to these pressures, regulators tend increasingly to conflate the conceptually distinct stages of standard-setting (setting long-run goals) and standard-using (achieving currently feasible levels of protection). The resulting aggregation of scientific, technical, economic, and political criteria is not only ad hoc, but also logically inscrutable. As a consequence, the meaning of the numerical value chosen for a given standard is ambiguous, representing neither a policy goal, nor a scientific 
judgment of health risk, nor even (in the case of national standards) a measure of the level of protection that can be reasonably achieved in specific local situations.

4. Taken together, the two suggestions discussed so far imply a regulatory model that relies less on law and more on self-regulation, voluntary compliance, and administrative discretion in technical interpretations. What are the functional requisites for a viable system of this kind? The following conditions seem to be essential: (1) a critical mass of highly qualified and incorruptible inspectors;

(2) a political culture predisposing people to accept a considerable amount of administrative discreticn; (3) the availability of significant penalties for serious violations; and (4) an active concern on the part of workers, management, and citizens at large for the quality of the ambient and workplace environment.

In a number of countries of Western Europe, these conditions are at least approximately satisfied. However, many American analysts doubt that a system of self-regulation and flexible inspection with participative and advisory cvertones would work in the United States. American inspectors do not share the prestige and long tradition of their European colleagues, and also their training is apparently not as good. The pre-OSHA experience with "consensus standards" voluntarily adopted by industry under lax supervision by the states has been sharply criticized by labor unions and public interest groups. Above all, the American polity is very reluctant to place discretion in the hands of its pubiic servants. The whole regulatory structure, an insightful referree has pointed out to me, is set up to protect the rights of the regulated from "arbitrary" shifts in position on the part of the administrators.

Clearly, any major reform of the present system raises serious questions of political feasibility. A thorough feasibility analysis is outside the scope of this note, but I shall try to indicate some of the costs of the 
institutional constraints under which the American system operates.

Mandatory standards focus the attention of operators and inspectors on a small set of permissible values and approved practices, at the expense of more comprehensive assessments of the overall quality of ambient or workplace environment. The logic of statutory control is such that it is difficult to differentiate between the important and the trivial, between form and substance. With no formal place for discretion in technical interpretations, the situation becomes one of either compliance or breach.

Moreover, given the limited knowledge available tolay in toxicology, radiation biology, epidemiology, and related fields, the numerical precision of current standards is spurious. At the same time, rigid statutory control does not allow the frequent revisions that a steady flow of new evidence would require. Nor can general regulations be written with enough specificity to accommodate all the unique conditions encountered in the millions of workplaces and thousands of communities of a large industrialized country. In fact, each major risk or health problem represents, in some sense, an exception; and we know that where an organization faces many exceptions and lacks a reliable body of knowledge from which solutions can be unambiguously derived, institutional arrangements approximating a professional model (equalitarian, flexible, allowing discretion) are more appropriate than the routinized, hierarchical patterns of bureaucracy. ${ }^{5)}$

5. The third direction of reform is concerned with what ilerbert Simon has called "procedural rationality". In situations characterized by great uncertainty and cognitive complexity, simon argues, "we must give an account not only of substantive rationality -- the extent to which appropriate courses of action are chosen -- but also of procedural rationality -the effectiveness, in light of human cognitive powers and limitations, of the procedures used to choose actions." 6 ) 
Policy analysis has been traditionally concerned with the problem of choosing the best means to achieve given ends. The basic conceptual categories of the policy analyst -- goals, alternatives, impacts, effectiveness, choice -- clearly reveal his deep commitment to a teleological conception of policy making. According to this conception, rationality means maximizing something; it means choosing the best alternative, subject to a set of constrainis. Hence the preoccupation with methods of analysis and evaluation that emphasize outcome rather than process, and the interest in what decisions are made, rather than in how they are made. As a result, policy analysis lacks the methodological equivalents of legal. notions like reasoned decision, proper form, and rules cif evidence.

This indifference toward procedures and the formal layout of arguments is justifiable under the assumption that there is "one best way" of making a decision or, if several methods are possible, that there is a well-defined rule for choosing among them. This is certainly not the situation in standard-setting. Here, Jerome Cornfield points out, "[a]1l present safety evaluation procedures ... must be regarded as mathematical formalisms whose correspondence with the realities of low dose effects is, and may long remain, largely conjectural."7) Thus, the most important problem is not determining the "correct" value for a certain standard -- is it 5 or 2 ppm? -- but which criteria and procedures should be used to choose among competing models, approaches, and regulatory philosophies.

In other vords, the main problem with many environmental policy decisions is not that they are, in some sense, suboptimal (we generally lack the scientific and medical knowleage to know what the correct decision should be), but that they leave much to be desired in terms of procedural rationality. Standard-settors often fail to probe deeply into the qualj.ty of the available eviderce, or to test the sensitivity of the chosen mociel to uncertainty and alternative assumptions. Even more commonly, the methodology 
used in reasoning from the data to a proposed standard is so informal that it is impossible to retrace the steps of the agency's argument and its factual basis. Again, the standard-setting process usually does not include any procedures specifically designed to bring out unstated assumptions, differing interpretations, and gaps in logic or in the empirical evidence.

An interesting example of procedural reform in the area of environmental regulation comes from the United States. Here the courts have developed "paper hearing" procedures that combine many of the advantages of a trialtype adversary process (without oral testimony and crossexamination), while avoiding undue costs and delays in decision-making. ${ }^{8)}$ Although procedural requirements are not by themselves sufficient to overcome the rigidity of the present system and its built-in tendency to become obsolete, they seem to have been fairly successful in improving the technical quality of environmental decision making. Data and technical studies are collected and organized more systematically; external criticism is explicitly taken into account so that policies reflect a broader range of considerations and interests; the various subunits of the regulatory agency are motivated to coordinate their assessments, methodologies, and conclusions. The new procedures should also increase the influence of the people who, because of their special knowledge, are more directly involved in standard-setting.

I would argue that the experience of the "paper hearing" procedures developed at EPA under the Clean Air Act has general relevance. The requirement of an open record that includes the factual and methodological bases of an agency's conclusions, as viell as external criticisin and responses to such criticism, is always a powerful incentive to more careful agency deliberations. The need to improve the intellectual quality of administrative deliberations is not, however, the only reason why procedural questions are so important today. In situaitons of great complexity 
and cognitive uncertainty it is essential that the groups affected should be willing to accept the outcome of the administrative process even before this has been determined. By ensuring adequate representation of conflicting opinions and examining a wide range of alternatives, well-designed procedures can greatly improve not only the rationality but also the legitimacy of regulatory decisions.

\section{Notes}

1. Safety and Health at Work, Report of the Committee, 1970-1972, Chairmar Lord Robens, London: H.M. Stationery office, Cm. 5034, 1972, pp. 44-46.

2. Ib., p. 48 .

3. Ib., p. 65 .

4. V.A. Rjazanov, "Criteria and methods for establishing maximum permissible concentrations of air pollution", Bulletin of the World Health organization, vol. 32, 1965, p. 390.

5. Charles Perrow, "A framework for the comparative analysis of organizations", American Sociological Review, vol. 32, 1967, pp. 194-208; J. Kenneth Benson, "The analysis of bureaucratic-professional conflict: functional versus dialectic approaches", The Sociological Quarterly, vol. 14, 1973, pp. 376-394.

6. Herbert A. Simon, "Rationality as process and as product of thought", American Economic Association Proceedings, vol. 68, May 1978, p. 90 (Simon's italics).

7. Jerome Cornfield, "Carcinogenic risk assessment", Science, vol. 198, 18 November 1977, p. 698.

8. W.F. Pedersen, Jr., "Formal records and informal rule making", Yale Law Journal, vol. 85, 1975, pp. 38-88. 